\title{
Human umbilical cord-derived mesenchymal stem cells and human cord blood mononuclear cells protect against cisplatin-induced acute kidney injury in rat models
}

\author{
QIAN XU $^{1 *}$, PING YAN $^{1 *}$, XIANG-JIE DUAN ${ }^{1 *}$, XI WU ${ }^{1}$, XIAO-JUN CHEN ${ }^{1}$, MIN LUO ${ }^{1}$, JING-CHENG PENG ${ }^{1}$, \\ LI-XIN FENG ${ }^{1}$, JIE LIU ${ }^{2}$, HUI-LIN ZHONG ${ }^{3}$, WEI CHENG ${ }^{1}$, QING-YAN ZOU ${ }^{3}$ and SHAO-BIN DUAN ${ }^{1}$ \\ ${ }^{1}$ Department of Nephrology, The Second Xiangya Hospital, Central South University, Hunan Key Laboratory of \\ Kidney Disease and Blood Purification, Changsha, Hunan 410011; ${ }^{2}$ Translational Center for Stem Cell Research, \\ Tongji Hospital, Tongji University School of Medicine, Shanghai, 200065; ${ }^{3}$ Neuromedical Research Center, \\ Guangdong 999 Brain Hospital, Guangzhou, Guangdong 510510, P.R. China
}

Received May 20, 2019; Accepted July 23, 2020

DOI: $10.3892 / \mathrm{etm} .2020 .9274$

\begin{abstract}
Human umbilical cord-derived mesenchymal stem cells (hUCMSCs) are a promising tool to attenuate cisplatin (CP)-induced acute kidney injury (AKI). However, whether the transplantation of human cord blood mononuclear cells (hCBMNCs) exhibits similar protective effects and their potential underlying mechanisms of action remain unclear. The present study aimed to determine the protective effects of hUCMSCs and hCBMNCs transplantation therapies on an established CP-induced rat model and explore their underlying mechanisms of action. A total of 24 Sprague-Dawley rats, selected based on body weight, were randomly assigned into 4 groups: i) normal control; ii) model (CP); iii) hCBMNCs (CP + hCBMNCs); and iv) hUCMSCs (CP + hUCMSCs). hUCMSCs $\left(2.0 \times 10^{6}\right.$ cells) and hCBMNCs $\left(2.0 \times 10^{6}\right.$ cells) were injected into the femoral vein of rats $24 \mathrm{~h}$ after CP $(8 \mathrm{mg} / \mathrm{kg})$ treatment. To determine the effects of hCBMNCs and hUCMSCs on CP-induced rats, renal function assessment and histological evaluations were performed. Expression levels of high mobility group box 1 (HMGB1) and the ratio of $\mathrm{Bax} / \mathrm{Bcl} 2$ in renal tissues were detected to elucidate their underlying molecular mechanisms of action. The results demonstrated that transplantation of hUCMSCs and hCBMNCs significantly improved renal function in CP-induced AKI rats, as evidenced by the enhancement of
\end{abstract}

Correspondence to: Professor Shao-Bin Duan, Department of Nephrology, The Second Xiangya Hospital, Central South University, Hunan Key Laboratory of Kidney Disease and Blood Purification, 139 Renmin Road, Changsha, Hunan 410011, P.R. China

E-mail: duansb528@csu.edu.cn

${ }^{*}$ Contributed equally

Key words: acute kidney injury, high mobility group box 1, apoptosis, stem cells, cisplatin renal morphology; decreased concentrations of blood urea nitrogen and serum creatinine; and a lower percentage of apoptotic renal tubular cells. The expression of HMGB1 and the ratio of $\mathrm{Bax} / \mathrm{Bcl}-2$ were significantly reduced in the hUCMSCs and hCBMNCs groups compared with CP group. In conclusion, the present study indicated that hCBMNCs exert similar protective effects to hUCMSCs on CP-induced AKI. hUCMSCs and hCBMNCs protect against CP-induced AKI by suppressing HMGB1 expression and preventing cell apoptosis.

\section{Introduction}

Acute kidney injury (AKI) refers to a broad spectrum of clinical conditions ranging from mild injury dysfunction to severe renal failure and can result in the permanent and complete loss of renal function (1). The pooled incidence of AKI in hospitalized patients in Eastern Asia (mainly including China, Japan and south Korea) is 15\% from 2004 to 2012 (2) and has been increasing over the past few decades (3). The incidence of AKI in critically ill patients worldwide ranges from 20 to $50 \%$, with a mortality rate as high as $50 \%$ since $2004(4,5)$, where continuous renal replacement therapy was used in $10-15 \%$ critically ill patients with AKI in a large multicenter study conducted in Finnish intensive care units and the Acute Kidney Injury-Epidemiologic Prospective Investigation study (6,7). Cisplatin (CP), a common cause of AKI, can induce the progression of chronic kidney disease if left untreated (8). Dose-dependent and cumulative nephrotoxicity are major side effects of this chemotherapeutic compound and patients often require a reduction in dose or discontinuation of treatment (9). A total of $\sim 1 / 3$ patients experience nephrotoxicity following an initial dose $\left(50-100 \mathrm{mg} / \mathrm{m}^{2}\right)$ of CP (10). The pathophysiological features of CP-induced AKI include proximal tubular injury (including apoptosis, autophagy, DNA damage and mitochondrial dysfunction), oxidative stress, inflammation and vascular injury in the kidneys (9).

Previous studies have demonstrated that inflammation and apoptotic cell death in renal tissues serve an important role 
in the progression of AKI (11-15). High mobility group box 1 (HMGB1) is an alarmin that is released by activated inflammatory cells, necrotic and apoptotic cells (16). HMGB1 has been shown to enhance the progression of acute injury $(17,18)$. Previous studies have reported that AKI induced by ischemia-reperfusion (19), CP (20) or folic acid (21) contribute to the release of HMGB1 in renal tissues, resulting in the promotion of the inflammatory response. Administration of exogenous HMGB1 aggravates kidney injury whereas HMGB1 inhibition significantly attenuates tubular injury and renal dysfunction (19). Furthermore, HMGB1 expression was previously found to be increased in a sepsis AKI mouse model with 5/6 nephrectomy where serum HMGB1 levels are positively associated with the severity of sepsis (22). These studies supported the notion that HMGB1 is a mediator of inflammation in AKI that can be used as an intervention target for AKI treatment.

Activation of the mitochondria-dependent apoptotic pathway also serves an important role in CP-induced nephrotoxicity, as evidenced by the upregulation of the pro-apoptotic protein $\mathrm{Bax}$ in renal tubular cells in a $\mathrm{CP}$-treated mouse model (23). CP-induced renal damage was found to be attenuated in Bax-knockout mice (23). In addition, Bcl-2, an anti-apoptotic protein, inhibits CP-induced Bax translocation, which suppresses apoptosis in T24R2 human bladder cancer cells (24). The protein ratio of Bax/Bcl-2 is associated with cell survival and apoptotic cell death in CP-treated proximal tubule cells (25).

Over the past decade, mesenchymal stem cells (MSCs) derived from bone marrow, umbilical cords and adipose tissues have been reported to be some of the most promising tools for treating AKI in various animal models, including CP-induced nephrotoxicity models (26-28). Compared with MSCs from other tissues, human umbilical cord-derived MSCs (hUCMSCs) can be separated from discarded umbilical cords, which are routinely harvested with no risk to donors and are rarely contaminated by infectious agents, including cytomegalovirus (29). Human cord blood mononuclear cells (hCBMNCs) are mononuclear cells (MNCs) derived from cord blood which exhibit similar advantages to hUCMSCs (30). hCBMNCs are composed of lymphocytes, hematopoietic stem cells, endothelial progenitor cells, monocytes and MSCs, which provides these cells with high regenerative and differentiation potentials (31).

While the protective effects of hUCMSCs against CP-induced AKI have been demonstrated, the role of hCBMNCs in renal diseases, particularly AKI, remain unknown. It is unclear whether hCBMNCs transplantation therapies exhibit similar protective effects and mechanisms of action. The present study aimed to investigate the protective effects of the transplantation of hUCMSCs and hCBMNCs on a CP-induced AKI rat model and elucidate the underlying molecular mechanisms of action. The results may provide experimental evidence for the future application of hUCMSCs and hCBMNCs for the treatment of patients with AKI.

\section{Materials and methods}

Sample collection. Umbilical cord and umbilical cord blood were collected from a 23-year-old woman in the Third Hospital of Guangdong Pharmaceutical University (Guangzhou, China) by Guangzhou Cedicine Biotechnology Co., Ltd. on March 12th, 2016. Umbilical cord blood was used to prepare hCBMNCs by Guangzhou Cedicine Biotechnology Co., Ltd. whilst umbilical cord was sent to Professor Jie Liu (China-US Research Center for Stem Cell, Shanghai, China) to prepare hUCMSCs. The project was carried out under the cooperation between the Second Xiangya Hospital and Guangzhou Cedicine Biotechnology Co., Ltd. Our study obtained the approval from the Medical Ethics Committee of the Second Xiangya Hospital of Central South University (Changsha, China) and written informed consent from the donor. Only one donor was recruited in our study. The present study was registered with the Chinese Clinical Trial Registry (November 1st, 2018; registration no. ChiCTR1800019254).

Preparation of hUCMSCs. Isolation and preparation of hUCMSCs were performed within $24 \mathrm{~h}$, as previously described (32). Briefly, hUCMSCs were identified according to expressed antigens CD90, CD73 and CD105 (33) using flow cytometry with the flow cytometer BD FACSCanto ${ }^{\mathrm{TM}}$ II (BD Biosciences). Fluorescently-labelled primary antibodies against CD90 [allophycocyanin (APC); cat. no. 17-0909-42; $5 \mu \mathrm{l} / \mathrm{ml}$ ], CD73 [phycoerythrin (PE); cat. no. 12-0739-42; $5 \mu \mathrm{l} / \mathrm{ml}$ ), CD105 (PE; cat. no. 12-1057-42; $5 \mu \mathrm{l} / \mathrm{ml}$ ), CD45 (FITC; cat. no. 11-0459-42; $5 \mu 1 / \mathrm{ml}$ ), CD34 (eFluor ${ }^{\circledR} 450$; cat. no. 48-0349-42; $5 \mu 1 / \mathrm{ml}$ ), CD133 (PE; cat. no. 12-1338-42; $5 \mu \mathrm{l} / \mathrm{ml}$ ), provided by Thermo Fishier Scientific. Inc., were used for flow cytometry. The cells were blocked in $1 \%$ bovine serum albumin (BSA; Affinity BioReagents, Thermo Fisher Scientific, Inc.) for $30 \mathrm{~min}$ at room temperature in the dark, washed with PBS twice and then incubated with the primary antibodies for $30 \mathrm{~min}$ at room temperature at a cell density of $3 \times 10^{7} / \mathrm{ml}$ prior to analysis. The data were analyzed using BD CellQuest ${ }^{\mathrm{TM}}$ software (version 5.1; BD Biosciences). The adipogenic, osteogenic and chondrogenic differentiation potentials were determined by using a Human Mesenchymal Stem Cell Functional Identification kit (R\&D Systems, Inc.) according to the manufacturer's protocol. The adhesive capacity of the hUCMSCs was observed under a fluorescence microscope (magnification, x40; Leica M205 FA; Leica Microsystems $\mathrm{GmbH})$.

Preparation of hCBMNCs. Umbilical cord blood was collected in $250 \mathrm{ml}$ standard blood collection bags (Baxter International, Inc.) containing citrate-phosphate-dextrose anticoagulant, as previously described (34). Briefly, samples were tested for pathogens of communicable diseases, including hepatitis B and C, human immunodeficiency virus, cytomegalovirus and Treponema pallidum within $24 \mathrm{~h}$ of collection. MNCs were isolated from the umbilical cord blood using Ficoll-Paque TM PLUS medium (Amersham Biosciences). Flow cytometry was used to examine the expressed antigens of hCBMNCs using a flow cytometer (BD FACSCanto ${ }^{\mathrm{TM}} \mathrm{II}$; BD Biosciences). Fluorescently-labelled primary antibodies against CD38 (PE-Cyanine7; cat. no. 25-0389-42; $5 \mu \mathrm{l} / \mathrm{ml}$ ), CD5 (PE; cat. no. 12-0059-42; $5 \mu \mathrm{l} / \mathrm{ml}$ ), CD3 (APC-eFluor ${ }^{\circledR}$ 780; cat. no. 47-0038-42; $5 \mu \mathrm{l} / \mathrm{ml}$ ), CD34 (eFluor ${ }^{\circledR} 450$; cat. no. 48-0349-42; $5 \mu 1 / \mathrm{ml}$ ), CD133 (PE; cat. no. 12-1338-42; $5 \mu \mathrm{l} / \mathrm{ml}$ ) provided by Thermo Fishier Scientific. Inc., were 
used for flow cytometry. The cells were blocked in $1 \%$ bovine serum albumin (BSA; Affinity BioReagents, Thermo Fisher Scientific, Inc.) for $30 \mathrm{~min}$ at room temperature in the dark, washed with PBS twice and then incubated with primary antibodies for $30 \mathrm{~min}$ at room temperature at a cell density of $3 \times 10^{7} / \mathrm{ml}$ prior to the analysis. The data were analyzed using BD CellQuest ${ }^{\mathrm{TM}}$ software (version 5.1; BD Biosciences). hCBMNCs were then collected and washed twice with DMEM, diluted to a cell density of $3 \times 10^{7} \mathrm{MNCs} / \mathrm{ml}$ and cryopreserved in sterile $2 \mathrm{ml}$ cryovials with $10 \%$ DMSO. Prior to cell transplantation, cell viability was evaluated using trypan blue assays before and then diluted with PBS (concentration, $\left.2 \times 10^{6} \mathrm{MNCs} / \mathrm{ml}\right)(35)$.

Study design. Male Sprague-Dawley rats (age, 8 weeks; weight, $250 \pm 10 \mathrm{~g}$ ) were obtained from Laboratory Animal Center of Southern Medical University (Guangzhou, China). All rats in experiments were provided free access to water and normal rat chow and were acclimatized for 7 days at $24^{\circ} \mathrm{C}$, $60 \pm 10 \%$ humidity and 12-h light/dark cycles before each animal experiment. To determine the effects of hUCMSCs and hCBMNCs on CP-induced AKI rats, 24 rats with similar body weights after 7 days of acclimatization $(310 \pm 10 \mathrm{~g})$ were selected and randomly assigned into 4 groups (n=6/group) as follows: i) normal control (CN); ii) model (CP); iii) hCBMNCs (CP + hCBMNCs); and iv) hUCMSCs (CP + hUCMSCs). AKI models were established by subcutaneous injections of the nephrotoxic drug CP (Qilu Pharmaceutical Co., Ltd.) at a dose of $8 \mathrm{mg} / \mathrm{kg}$. hUCMSCs $\left(2.0 \times 10^{6}\right.$ cells $)$ and hCBMNCs $\left(2.0 \times 10^{6}\right.$ cells) were injected into the femoral vein of rats $24 \mathrm{~h}$ following $\mathrm{CP}$ treatment. On day 5 following $\mathrm{CP}$ injection, all rats were intraperitoneally injected with $2 \%$ pentobarbital sodium $(45 \mathrm{mg} / \mathrm{kg})$ for anesthesia. Following the collection of $2 \mathrm{ml}$ blood from the auricula dextra, rats were sacrificed by exsanguination. All animal-related operations were conducted under the approval of the Animal Care and Use Committee of the Second Xiangya Hospital, Central South University, Changsha, China (approval no. SYXK(Xiang) 2017-0002).

Measurement of blood urea nitrogen (BUN) and creatinine. Blood samples were collected for BUN and serum creatinine (SCr) measurements on days 0,3 and 5 following CP injection. On days 0 and $3,1 \mathrm{ml}$ blood was collected from the orbital venous plexus after inhalation anesthesia with $5 \%$ isoflurane. Blood collection was performed within 2 min. Rats were then put back to their cages to keep raising after compression hemostasis and provided free access to water and normal rat chow. On day 5, $2 \mathrm{ml}$ blood was collected from the auricula dextra after anesthesia with an intraperitoneal injection of $2 \%$ pentobarbital sodium $(45 \mathrm{mg} / \mathrm{kg}$ ) for anesthesia, where the blood collection was done within $10 \mathrm{~min}$. Rats were sacrificed by exsanguination after blood collection. Death was confirmed by the absence of heartbeat. BUN and SCr levels were determined using an automatic biochemical analyzer (Shimadzu Corporation; CL-8000) at the Chinese Academy of Sciences Guangzhou Institute of Biomedicine and Health Laboratory Animal Center.

Renal histological evaluation. Right kidneys were fixed with $10 \%$ buffered formalin for $24 \mathrm{~h}$ at room temperature and embedded in paraffin. Subsequently, kidney samples were cut into $3 \mu \mathrm{m}$ thick sections and stained with hematoxylin and eosin at room temperature for 15 and $3 \mathrm{~min}$, respectively. Histological changes were observed and semi-quantitative scoring was performed. A minimum of 10 fields were assessed and graded per biopsy using a light microscope (magnification, x200; BX51TF; Olympus Corporation). For tubular injury assessment, the following scale was used: i) 0 , no tubular injury; ii) $1,<25 \%$ of tubules injured; iii) $2,25-50 \%$ of tubules injured; iv) $3,51-75 \%$ of tubules injured; and v) $4, \geq 76 \%$ of tubules injured (36).

Apoptosis analysis of renal tubular epithelial cells. Renal samples were fixed in $10 \%$ buffered formalin as aforementioned. Apoptotic cells in renal tissue were quantified by terminal deoxynucleotidyl transferase dUTP nick end labeling (TUNEL) assays using an in situ cell detection kit (TdT-FragEL ${ }^{\text {TM }}$ DNA fragmentation detection kit; Merck $\mathrm{KGaA}$ ) according to the manufacturer's protocol. At room temperature, renal sections were labeled with biotin-dUTP for $60 \mathrm{~min}$ and combined with streptavidin-horseradish peroxidase for $10 \mathrm{~min}$. They were then labeled with 3,3' diaminobenzidine (Dako; Agilent Technologies, Inc.) for $10 \mathrm{~min}$, counterstained with methyl green (Vector Laboratories, Inc.; Maravai LifeSciences) for $1 \mathrm{~min}$ at room temperature and mounted with glycerinum (Beyotime Institute of Biotechnology). To compare the abundance of TUNEL-positive renal tubular cells among groups, 10 different fields from each group were chosen and $1 \times 10^{2}$ renal tubular epithelial cells in each group were examined by a light microscope (magnification, x200; BX51TF; Olympus Corporation). Tubular apoptosis was evaluated by counting TUNEL-positive cells. The obtained results are presented as TUNEL positive cells per $1 \times 10^{2}$ renal tubular cells.

Expression of high mobility group box 1 (HMGB1) and $B a x / B c l 2$ in renal tissues. Protein expression levels of HMGB1 in renal tissues were detected using Rat HMGB-1 ELISA Kit (cat. no. E-EL-R0505c; Elabscience, Inc.) and western blotting (Affinity BioReagents; Thermo Fisher Scientific, Inc.). Protein expression levels of Bax and Bcl-2 in renal tissues were examined by western blotting.

Briefly, $100 \mathrm{mg}$ samples of subpolar tissues from right kidneys were treated with a mixture of ice-cold RIPA lysis buffer and PMSF (100:1; Beyotime Institute of Biotechnology) for $60 \mathrm{~min}$ and centrifugated at $10,000 \mathrm{x} \mathrm{g}$ for $20 \mathrm{~min}$ at $4^{\circ} \mathrm{C}$. Supernatants were collected and stored at $-70^{\circ} \mathrm{C}$. Protein concentrations were determined using a bicinchoninic acid Protein Assay Reagent kit (Beyotime Institute of Biotechnology). Following this, protein samples $(50 \mu \mathrm{g}$ protein/lane) were loaded, separated by $12 \%$ SDS-PAGE and transferred to nitrocellulose filter membranes. Membranes were blocked by incubation with TBS-T (TBS with $0.05 \%$ Tween-20, pH 7.4) and 5\% BSA (Affinity BioReagents, Thermo Fisher Scientific, Inc.) at room temperature for $1 \mathrm{~h}$. Following this, membranes were incubated with HMGB1 (cat. no. PA5-27378), Bax (cat. no. PA5-39778) and Bcl-2 (cat. no. PA5-27094) primary antibodies (polyclonal; rabbit anti-rat; 1:1,000, Affinity BioReagents; Thermo Fisher Scientific, Inc.) and anti- $\beta$-actin antibodies (polyclonal; rabbit 


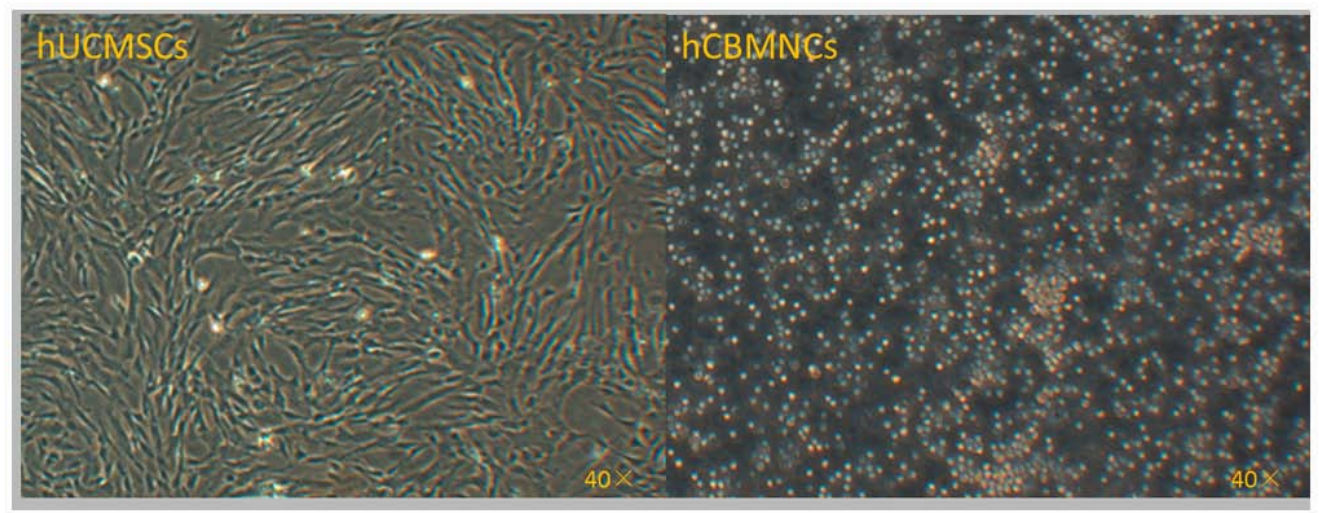

Figure 1. Morphology of the human cord blood mononuclear cell and human umbilical cord-derived mesenchymal stem cells.

Table I. Changes in the levels of BUN and SCr in each group.

\begin{tabular}{|c|c|c|c|c|}
\hline \multicolumn{5}{|c|}{ A, BUN } \\
\hline \multirow[b]{2}{*}{ Day } & \multicolumn{2}{|c|}{ Group } & \multirow[b]{2}{*}{ hCBMNCs } & \multirow[b]{2}{*}{ hUCMSCs } \\
\hline & $\mathrm{CN}$ & $\mathrm{CP}$ & & \\
\hline 0 & $7.15 \pm 1.24$ & $6.41 \pm 1.08$ & $5.13 \pm 1.51$ & $6.92 \pm 1.73$ \\
\hline 3 & $6.09 \pm 1.31$ & $31.14 \pm 7.75^{\mathrm{a}}$ & $19.98 \pm 7.56^{\mathrm{a}, \mathrm{b}}$ & $20.16 \pm 10.99^{a, b}$ \\
\hline 5 & $5.28 \pm 1.83$ & $56.97 \pm 15.55^{\mathrm{a}}$ & $29.39 \pm 18.10^{\mathrm{a}, \mathrm{c}}$ & $41.02 \pm 13.27^{\mathrm{a}, \mathrm{b}}$ \\
\hline
\end{tabular}

$\mathrm{B}, \mathrm{SCr}$

\begin{tabular}{lcccc}
\hline & \multicolumn{3}{c}{ Group } & \\
\cline { 2 - 3 } Day & $\mathrm{CN}$ & $\mathrm{CP}$ & hCBMNCs & hUCMSCs \\
\hline 0 & $20.82 \pm 3.22$ & $21.35 \pm 1.59$ & $18.95 \pm 3.99$ & $20.83 \pm 2.97$ \\
3 & $19.15 \pm 4.78$ & $122.52 \pm 41.6^{\mathrm{a}}$ & $65.52 \pm 21.18^{\mathrm{a}, \mathrm{c}}$ & $68.73 \pm 21.52^{\mathrm{a}, \mathrm{c}}$ \\
5 & $19.50 \pm 8.39$ & $206.87 \pm 57.7^{\mathrm{a}}$ & $140.25 \pm 38.2^{\mathrm{a}, \mathrm{c}}$ & $148.38 \pm 30.77^{\mathrm{a}, \mathrm{c}}$ \\
\hline
\end{tabular}

Data are presented as the mean $\pm \mathrm{SD}$. ${ }^{\mathrm{a}} \mathrm{P}<0.01$ vs. the $\mathrm{CN}$ group. ${ }^{\mathrm{b}} \mathrm{P}<0.05$ vs. the $\mathrm{CP}$ group. ${ }^{\mathrm{c}} \mathrm{P}<0.01$ vs. the $\mathrm{CP}$ group. $\mathrm{BUN}$, blood urea nitrogen; $\mathrm{SCr}$, serum creatinine; $\mathrm{CN}$, normal control; $\mathrm{CP}$, cisplatin model; hCBMNCs, human cord blood mononuclear cells $(\mathrm{CP}+\mathrm{hCBMNCs})$; hUCMSCs, human umbilical cord-derived mesenchymal stem cells (CP + hUCMSCs).

anti-rat; 1:2,000; Santa Cruz Biotechnology, Inc.) at $4^{\circ} \mathrm{C}$ overnight with shaking. Membranes were rinsed with TBST 4 times and incubated with horseradish peroxidase-conjugated secondary antibodies (1:5,000; cat. no. ab98364; Abcam). Finally, protein bands were detected using ECL western blotting detection reagent (EMD Millipore) and quantified using Tanon 5200 Multi Image Analysis software 1.0 (Tanon Science \& Technology Co., Ltd.).

Statistical analysis. SPSS Statistics software (version 20.0; IBM Corp.) was used for statistical analyses. Data are presented as mean \pm standard deviation. Data were analyzed using one-way ANOVA and two-group comparisons among multiple samples was analyzed using Tukey's multiple comparison test. $\mathrm{P}<0.05$ was considered to indicate a statistically significant difference.

\section{Results}

Phenotypic characterization and flow cytometric analysis of isolated hUCMSCs and hCBMNCs. hUCMSCs were spindle shaped and arranged in a radial pattern following passage, hCBMNCs did not adhere and exhibited a single or multiple cell aggregate suspension state (Fig. 1). Flow cytometric analysis revealed that hUCMSCs were positive for CD90, CD73 and CD105 and negative for CD45, CD34 and CD133. The percentage of CD90, CD73 and CD105 positive cells were $83.00,82.25$ and $80.11 \%$, respectively, whilst CD45, CD34 and CD133 were only expressed in $4.08,1.31$ and $0.70 \%$ of hUCMSCs, respectively (data not shown). A clonal hUCMSCs population was chosen for following experiments and used at passage 4. hCBMNCs mainly expressed CD38, CD5 and CD3 with the positive rates being 39.32 , 38.50 and $41.10 \%$, 

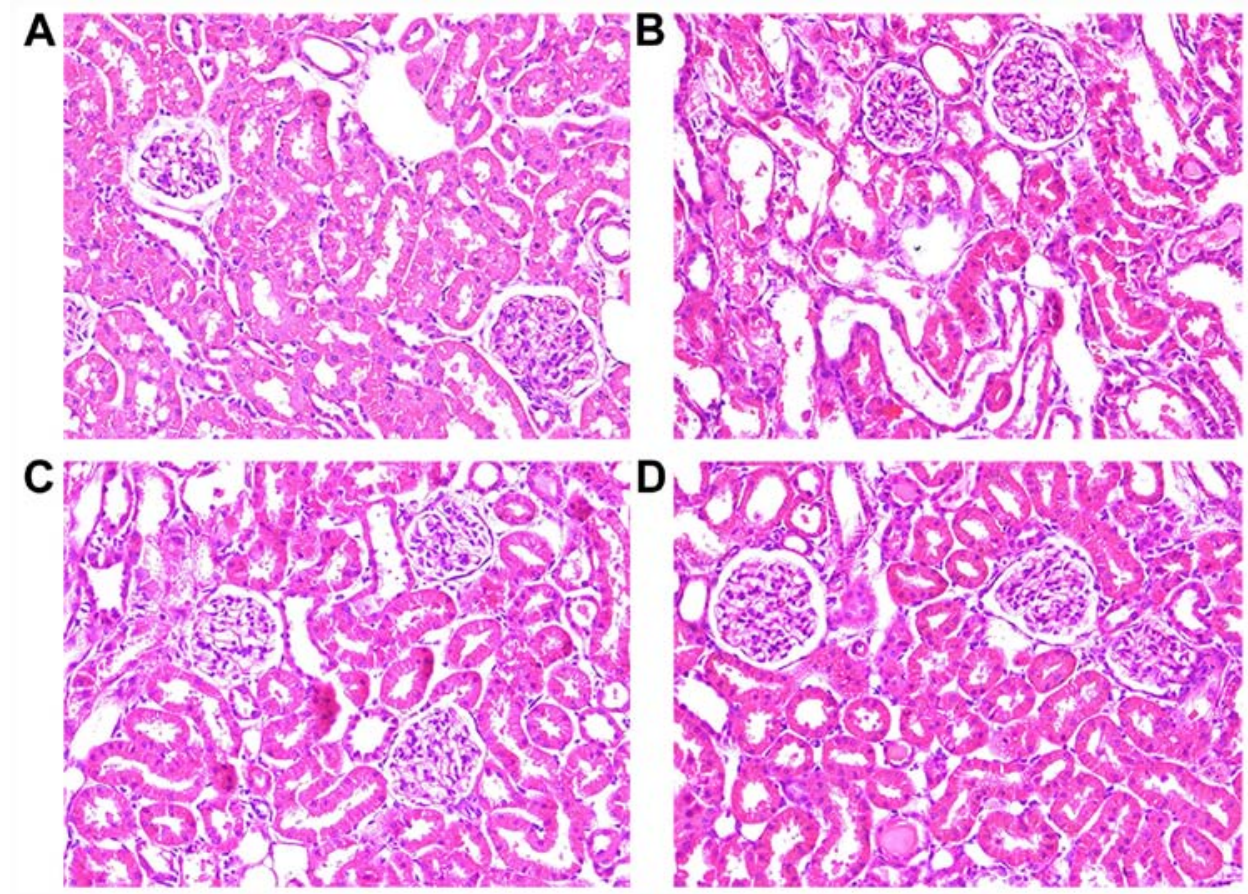

Figure 2. Representative images of renal histomorphological changes. (A) Normal control group. On day 5 following cisplatin injections, kidney tissues from the (B) model group exhibited swelling, vacuolar degeneration, necrosis of tubular epithelial cells, tubular dilation, protein-cast formation, and loss of the tubular brush border. Kidney tissues from the (C) human cord blood mononuclear cell and (D) human umbilical cord-derived mesenchymal stem cell groups presented marked attenuation of renal tubular damage, with only mild loss of the tubular brush border, swelling and vacuolar degeneration in focal tubular epithelial cells. Arrow 1 indicates the location of the loss of the tubular brush border; arrow 2 indicates the location of cast formation; arrow 3 indicates the location of tubular dilation; arrow 4 indicates the location of vacuolar degeneration. Magnification, $\mathrm{x} 200$.

Table II. Semi-quantitative analysis of renal tubular damage in each group.

\begin{tabular}{lcc}
\hline Group & Tubular injury score & $\begin{array}{c}\text { Apoptosis of renal tubular } \\
\text { epithelial cells, } \%\end{array}$ \\
\hline $\mathrm{CN}$ & $0.1 \pm 0.316$ & $1.3 \pm 0.949$ \\
$\mathrm{CP}$ & $2.5 \pm 0.527^{\mathrm{a}}$ & $12.5 \pm 1.08^{\mathrm{a}}$ \\
hCBMNCs & $1.7 \pm 0.675^{\mathrm{a}, \mathrm{b}}$ & $6.1 \pm 1.524^{\mathrm{a}, \mathrm{c}}$ \\
hUCMSCs & $1.6 \pm 0.699^{\mathrm{a}, \mathrm{b}}$ & $6.6 \pm 0.843^{\mathrm{a}, \mathrm{c}}$ \\
\hline
\end{tabular}

Data are presented as mean $\pm \mathrm{SD} .{ }^{\mathrm{a}} \mathrm{P}<0.01$ vs. the $\mathrm{CN}$ group. ${ }^{\mathrm{b}} \mathrm{P}<0.05$ vs. the $\mathrm{CP}$ group. ${ }^{\mathrm{c}} \mathrm{P}<0.01$ vs. the $\mathrm{CP}$ group. $\mathrm{CN}$, normal control; $\mathrm{CP}$, cisplatin model; hCBMNCs, human cord blood mononuclear cells $(\mathrm{CP}+\mathrm{hCBMNCs})$; hUCMSCs, human umbilical cord-derived mesenchymal stem cells (CP + hUCMSCs).

respectively; whilst $2.11 \%$ hCBMNCs expressed CD34 and $2.31 \%$ expressed CD133 (data not shown).

Changes in BUN and SCr levels. Compared with the CN group, $\mathrm{BUN}$ and $\mathrm{SCr}$ levels in the $\mathrm{CP}$ group were significantly raised on day 3 and 5 following $C P$ injection $(\mathrm{P}<0.01)$. The levels of BUN ( $\mathrm{P}<0.05$, hUCMSCs vs. $\mathrm{CP} ; \mathrm{P}<0.01$, hCBMNCs vs. $\mathrm{CP}$ group) and $\mathrm{SCr}(\mathrm{P}<0.01)$ in the hUCMSCs and hCBMNCs groups were significantly decreased compared with those in the CP group on day 5. There were no significant differences in BUN and SCr levels between the hUCMSCs and hCBMNCs group (Table I).
Renal histopathology. The morphology of renal tubules was normal in normal control group (Fig. 2A). No tubular dilation, cast formation or vacuolar degeneration of tubular epithelial cells were observed. However, vacuolar degeneration, tubular dilation, cast formation and loss of the tubular brush border were observed in CP-injected rats (Fig. 2B). Rats treated with hCBMNCs (Fig. 2C) or hUCMSCs (Fig. 2D) exhibited a mild loss of the tubular brush border and cast formation in focal tubular epithelial cells. Semi-quantitative analysis of the tubular injury score in renal tissues revealed that renal tubular damage was significantly aggravated in the model, hUCMSCs and hCBMNCs groups compared with that in the normal control group $(\mathrm{P}<0.01$; Table II). Tubular injury score was found to be significantly attenuated in rats injected with hUCMSCs or hCBMNCs compared with the CP group $(\mathrm{P}<0.05$; Table II). There were no significant difference in the severity of renal tubular damage between the hUCMSCs and hCBMNCs groups $(\mathrm{P}>0.05)$.

Apoptosis of renal tubular epithelial cells. TUNEL staining was performed to detect apoptosis of renal tubular epithelial cells. Cells with brownish yellow granules in the nucleus were considered to be apoptotic renal tubular epithelial cells. Apoptotic renal tubular epithelial cells were not observed in the normal control group (Fig. 3A) but could be seen in hUCMSCs or hCBMNCs group (Fig. 3C and D), and were widely distributed in the renal tubules of the model group (Fig. 3B). Semi-quantitative analysis showed that the percentage of apoptotic renal tubular cells in the hUCMSCs and hCBMNCs groups were significantly increased compared 

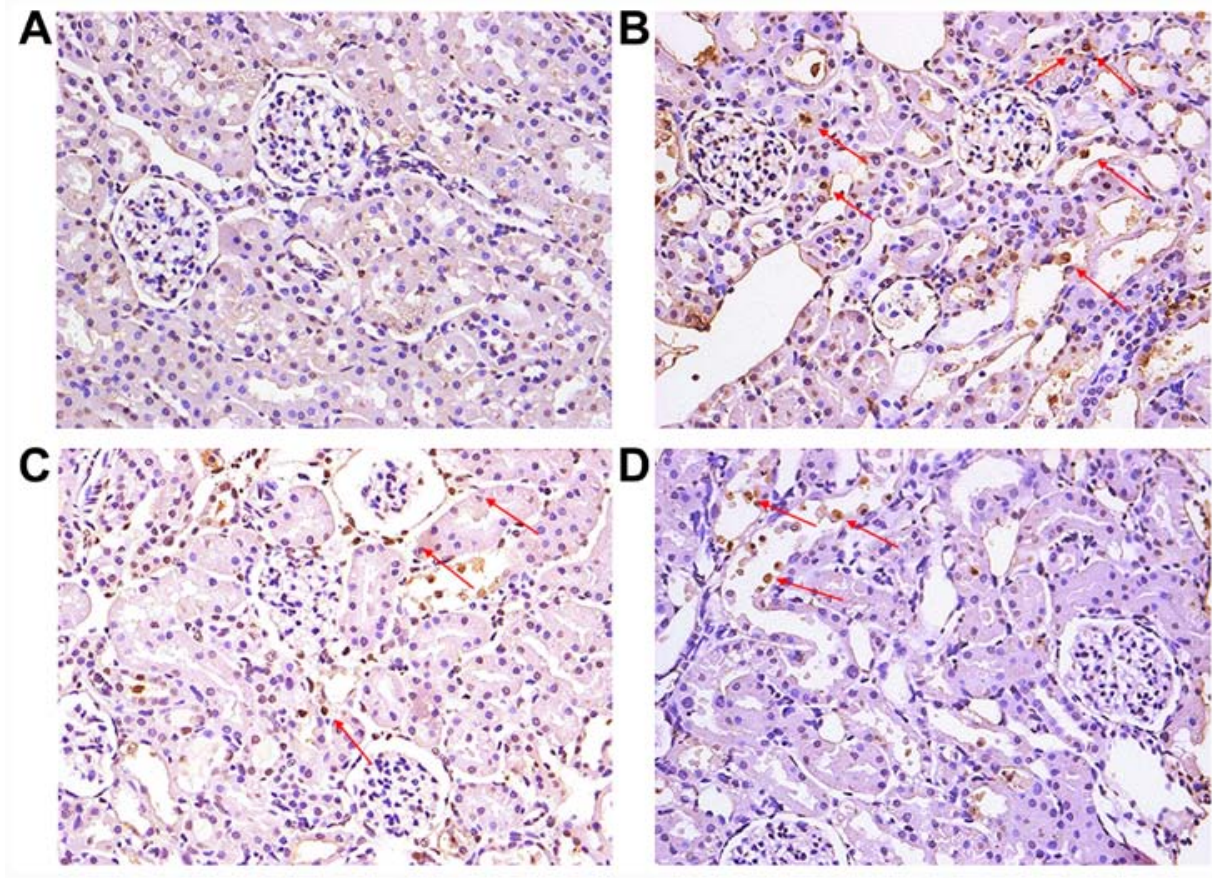

Figure 3. Representative images of apoptotic characteristics of renal tubular epithelial cells. (A) normal control group. (B) model group. (C) human cord blood mononuclear cell group. (D) human umbilical cord-derived mesenchymal stem cell group. Arrows indicate representative apoptotic cells. Cells with brownish yellow granules in the nucleus were considered apoptotic. Magnification, x200.

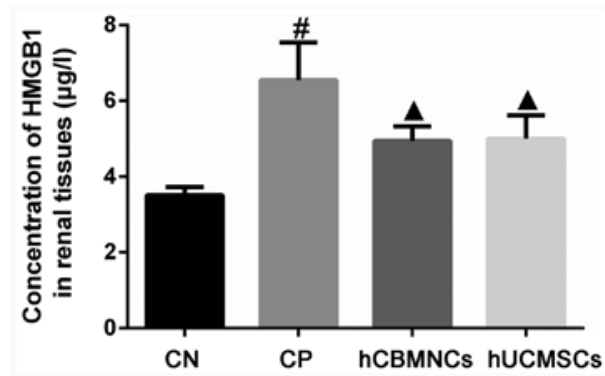

Figure 4. Changes in HMGB1 concentrations in the renal tissues of each group $(\mu \mathrm{g} / \mathrm{l})$. HMGB1 concentrations were determined by ELISA. Data are presented as the mean $\pm \mathrm{SD}$ ( $\mathrm{n}=6$ /group). ${ }^{*} \mathrm{P}<0.01$ vs. the $\mathrm{CN}$ group. ${ }^{\wedge} \mathrm{P}<0.01$ vs. the $\mathrm{CP}$ group. HMGB1, high mobility group box $1 ; \mathrm{CN}$, normal control; $\mathrm{CP}$, cisplatin model; hCBMNCs, human cord blood mononuclear cells; hUCMSCs, human umbilical cord-derived mesenchymal stem cells.

with the normal control group ( $\mathrm{P}<0.01 ;$ Fig. 3 and Table II $)$ and significantly decreased compared with model group $(\mathrm{P}<0.01)$.

Protein expression of HMGB1, Bcl-2 and Bax, in renal tissues. $\mathrm{CP}$ administration significantly increased the expression levels of HMGB1 in renal tissues in the CP group compared with CN group (Fig. 4; $\mathrm{P}<0.01$ ). Furthermore, treatment with hCBMNCs and hUCMSCs significantly downregulated HMGB1 in renal tissues compared with the $\mathrm{CP}$ group $(\mathrm{P}<0.01)$. Western blotting results demonstrated that the ratio of $\mathrm{Bax} / \mathrm{Bcl}-2$ and the expression of HMGB1 were significantly higher in the CP group compared with the $\mathrm{CN}$ group $(\mathrm{P}<0.01$; Figs. 5 and 6$)$. Additionally, in both the hUCMSCs group or hCBMNCs group, the expression of HMGB1 and ratio of Bax/Bcl-2 were significantly lower in the hUCMSCs and hCBMNCs groups compared with the CP group $(\mathrm{P}<0.01)$.
A

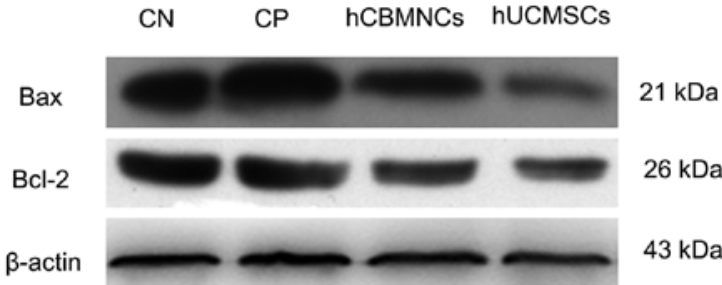

B

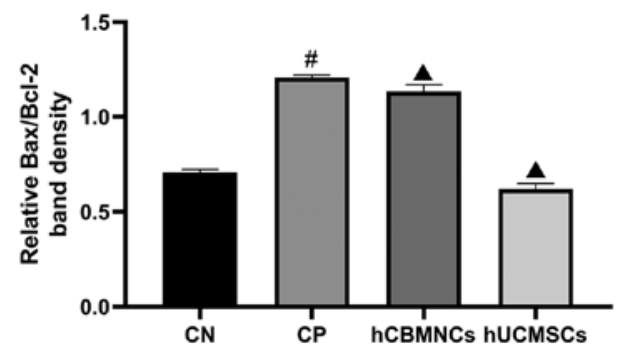

Figure 5. Changes in Bax and Bcl-2 protein expression in the renal tissues of each group. (A) Protein levels of Bax and Bcl-2 were measured using western blotting. (B) Protein bands were quantified using Tanon 5200 Multi Image Analysis software and relative Bax/Bcl-2 band densities were measured. Data are presented as the mean $\pm \mathrm{SD}$ (n=6/group). ${ }^{~} \mathrm{P}<0.01$ vs. the $\mathrm{CN}$ group. ${ }^{\wedge} \mathrm{P}<0.01$ vs. the $\mathrm{CP}$ group. $\mathrm{CN}$, normal control; $\mathrm{CP}$, cisplatin model; hCBMNCs, human cord blood mononuclear cells; hUCMSCs, human umbilical cord-derived mesenchymal stem cells.

\section{Discussion}

The results of the present study demonstrated that hUCMSCs and hCBMNCs exhibited similar protective effects in $\mathrm{CP}$-induced AKI rats. These protective effects may be associated with HMGB1 downregulation and a decreased Bax/Bcl-2 ratio. 


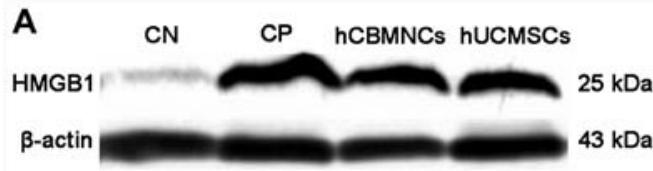

B

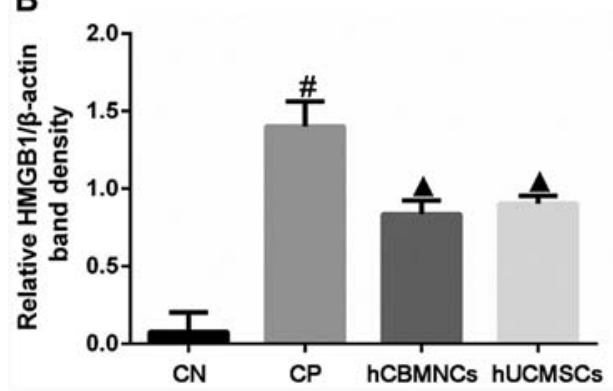

Figure 6. Protein expression of HMGB1 in the renal tissues of each group. (A) Protein levels of HMBG1 were measured using western blotting. (B) Protein bands were quantified using Tanon 5200 Multi Image Analysis software and relative $\mathrm{HMGB} 1 / \beta$-actin band densities were measured. Data are presented as the mean $\pm \mathrm{SD}$ (n=6/group). ${ }^{\prime \prime} \mathrm{P}<0.01$ vs. the $\mathrm{CN}$ group. $\triangle \mathrm{P}<0.01$ vs. the $\mathrm{CP}$ group. HMGB1, high mobility group box $1 ; \mathrm{CN}$, normal control; CP, cisplatin model; hCBMNCs, human cord blood mononuclear cells; hUCMSCs, human umbilical cord-derived mesenchymal stem cells.

Due to the widespread use of $\mathrm{CP}$ and other platinum derivatives as chemotherapeutic agents to treat solid tumors, CP-induced AKI has become a common side effect and accounts for $8-60 \%$ of hospital-acquired cases of AKI (37). $\mathrm{CP}$-induced AKI is characterized by renal tubular epithelial cell injury, renal dysfunction and high mortality with no effective prevention measures (9). Clinically, CP-induced nephrotoxicity is mainly prevented by hydration therapy, proper administration times and dose restriction (38). However, the occurrence of CP-induced kidney injury remains high (39). Therefore, the development of novel and effective strategies for CP-induced AKI are urgently needed.

MSCs are a group of undifferentiated pluripotent cells in higher organisms that have been widely employed in the research of human diseases (40-43). Previous studies have demonstrated that MSCs significantly improve the survival rate and renal function in $\mathrm{CP}$-induced $\mathrm{AKI}$ animal models with normal or compromised immune systems $(44,45)$. Another previous study has reported that early, rather than late, treatment with hUCMSCs attenuates CP-induced nephrotoxicity through immunomodulation (46). Jiao et al (28) revealed that bone marrow MSC-derived conditioned medium prevented $\mathrm{CP}$-induced AKI through the activation of the $\mathrm{Wnt} / \beta$-catenin pathway. However, few studies have compared the effects of hUCMSCs and hCBMNCs on CP-induced AKI. The present study evaluated the therapeutic potentials of hUCMSCs and hCBMNCs in CP-induced AKI in rat models. The results demonstrated that hUCMSCs and hCBMNCs significantly improved renal function, as evidenced by improved renal morphology; decreased concentrations of BUN and SCr; and a reduced percentage of apoptotic renal tubular cells. This indicated that hUCMSCs and hCBMNCs had protective effects on $\mathrm{CP}$-induced AKI rats. Following this, the possible mechanisms underlying the renoprotective effects of hUCMSCs and hCBMNCs on CP-induced AKI were further investigated in the present study.
The present study demonstrated that renal HMGB1 protein expression was significantly upregulated in rats with $\mathrm{CP}$-induced renal toxicity. However, in rats administrated with hUCMSCs or hCBMNCs, HMGB1 expression levels decreased significantly compared with the CP group, indicating that hUCMSCs or hCBMNCs may protect against $\mathrm{CP}$-induced $\mathrm{AKI}$ in rat models by suppressing the release of HMGB1. CP also significantly increased the number of TUNEL-positive cells and the $\mathrm{Bax} / \mathrm{Bcl}-2$ ratio. Additionally, the results demonstrated that the number of TUNEL-positive cells and the ratio of $\mathrm{Bax} / \mathrm{Bcl}-2$ decreased in rats treated with hUCMSCs or hCBMNCs. These results suggested alleviated kidney tissue injury and improved renal function. The present study confirmed the role of $\mathrm{Bax} / \mathrm{Bcl}-2$ in $\mathrm{CP}$-induced AKI demonstrated in previous studies $(24,25,47)$, where the level of Bax was shown to be upregulated during CP treatment accompanied with the release of mitochondrial cytochrome $c$ and cell apoptosis. This indicates the involvement of the intrinsic pathway of apoptosis in CP-induced nephrotoxicity $(25,47)$, Bcl-2 downregulation by RNA interference potentiates the redistribution of Bax and cytochrome $c$ and promotes apoptosis (24). The present study further indicated that hUCMSCs and hCBMNCs attenuated $\mathrm{CP}$-induced nephrotoxicity by inhibiting apoptosis in renal tubular cells and reducing the $\mathrm{Bax} / \mathrm{Bcl}-2$ ratio.

However, it is unknown whether this protective effect is due to the local action or a systemic effect of the MSCs. It has been reported that stem cells exert therapeutic effects via two distinct mechanisms: i) differentiation into target tissue cells; and ii) secretion of regulatory factors (48). Previous studies have demonstrated that stem cell-mediated protection is a result of their ability to engraft into a damaged kidney $(44,49)$ and PKH-26-labeled hUCMSCs have been detected in CP-injured kidneys (46). By contrast, other studies have reported that the beneficial effect of stem cells is mediated through paracrine activities, in which MSCs produce various cytokines and growth factors, including VEGF $(50,51)$. Furthermore, the administration of secreted microvesicles from stem cells loaded with mRNA and microRNA alleviates renal tubular injury and improves renal function in models of AKI $(52,53)$. Due to the inconsistencies in the reported mechanisms of action behind the renoprotective effects of stem cells by previous studies, it is crucial to further investigate whether the renoprotective effect of stem cells are associated with local or systemic effects, or a combination of both.

The present study had certain limitations. Firstly, there was a lack of in vitro and clinical experiments to support the animal experiments. Secondly, the distribution of stem cells in the renal tissues of AKI models were not observed. Thirdly, the possible role of HMGB1 in the renoprotective mechanisms of action of hUCMSCs and hCBMNCs requires further verification by gene silencing or knockout experiments. Therefore, future work should focus on elucidating the renoprotective mechanisms of action of hUCMSCs and hCBMNCs, as well as the functional role of HMGB1 and relevant signaling pathways, which could confirm the results of the current study.

In conclusion, the present study demonstrated that hUCMSCs and hCBMNCs exert similar renoprotective effects on CP-induced AKI rat models. The renoprotective mechanisms of action may be associated with HMGB1 downregulation, 
anti-apoptosis in renal tubular cells and a decrease in the Bax/Bcl-2 ratio. Transplantation of hUCMSCs and hCBMNCs may be a potential novel therapy for patients with AKI.

\section{Acknowledgements}

Not applicable.

\section{Funding}

The present study was supported by the Clinical Medical Technology Innovation Guide Project of Hunan Province (grant no. 2017SK50117), the National Natural Science Foundation of China (grant no. 81570618), the Development and Reform Commission of Hunan Province (grant no. 2014-658) and the Scientific Foundation of Hunan Province (grant no. S2013F1022).

\section{Availability of data and materials}

The datasets used and/or analyzed during the current study are available from the corresponding author on reasonable request.

\section{Authors' contributions}

SBD designed the present study and revised the manuscript critically for important intellectual content. QX, PY and XJD acquired, analyzed and interpreted the data, and drafted the manuscript. XW, XJC, ML, JCP, LXF and WC analyzed and interpreted the data, and revised the manuscript critically for important intellectual content. JL provided the hUCMSCs, analyzed and interpreted the data, and revised the manuscript critically for important intellectual content. HLZ and QYZ provided the hCBMNCs, analyzed and interpreted the data, and revised the manuscript critically for important intellectual content. All authors read and approved the final manuscript, and agreed to be accountable for all aspects of the work.

\section{Ethics approval and consent to participate}

All animal experimental procedures and protocols were approved by the Animal Care and Use Committee of the Second Xiangya Hospital, Central South University, Changsha, China. Human umbilical cords were collected after obtaining written informed consent from the donors with institutional review board approval.

\section{Patient consent for publication}

Not applicable.

\section{Competing interests}

The authors declare that they have no competing interests.

\section{References}

1. Hoste EAJ, Kellum JA, Selby NM, Zarbock A, Palevsky PM Bagshaw SM, Goldstein SL, Cerdá J and Chawla LS: Global epidemiology and outcomes of acute kidney injury. Nat Rev Nephrol 14: 607-625, 2018
2. Susantitaphong P, Cruz DN, Cerda J, Abulfaraj M, Alqahtani F, Koulouridis I, Jaber BL and Acute Kidney Injury Advisory Group of the American Society of Nephrology: World incidence of AKI: A meta-analysis. Clin J Am Soc Nephrol 8: 1482-1493, 2013.

3. Negi S, Koreeda D, Kobayashi S, Yano T, Tatsuta K, Mima T, Shigematsu T and Ohya M: Acute kidney injury: Epidemiology, outcomes, complications, and therapeutic strategies. Semin Dial 31: 519-527, 2018.

4. Schiffl H, Lang SM and Fischer R: Long-term outcomes of survivors of ICU acute kidney injury requiring renal replacement therapy: A 10-year prospective cohort study. Clin Kidney J 5: 297-302, 2012.

5. Case J, Khan S, Khalid R and Khan A: Epidemiology of acute kidney injury in the intensive care unit. Crit Care Res Pract 2013: 479730, 2013.

6. Nisula S, Kaukonen KM, Vaara ST, Korhonen AM, Poukkanen M, Karlsson S, Haapio M, Inkinen O, Parviainen I, Suojaranta-Ylinen R, et al: Incidence, risk factors and 90-day mortality of patients with acute kidney injury in finnish intensive care units: The FINNAKI study. Intensive Care Med 39: 420-428, 2013.

7. Hoste EA, Bagshaw SM, Bellomo R, Cely CM, Colman R, Cruz DN, Edipidis K, Forni LG, Gomersall CD, Govil D, et al: Epidemiology of acute kidney injury in critically ill patients: The multinational AKI-EPI study. Intensive Care Med 41: 1411-1423, 2015.

8. Uchino S, Kellum JA, Bellomo R, Doig GS, Morimatsu H, Morgera S, Schetz M, Tan I, Bouman C, Macedo E, et al: Acute renal failure in critically ill patients: A multinational, multicenter study. JAMA 294: 813-818, 2005.

9. Ozkok A and Edelstein CL: Pathophysiology of cisplatin-induced acute kidney injury. Biomed Res Int 2014: 967826, 2014.

10. Shiraishi F, Curtis LM, Truong L, Poss K, Visner GA, Madsen K, Nick HS and Agarwal A: Heme oxygenase-1 gene ablation or expression modulates cisplatin-induced renal tubular apoptosis. Am J Physiol Renal Physiol 278: F726-F736, 2000.

11. Zhang B, Ramesh G, Uematsu S, Akira S and Reeves WB: TLR4 signaling mediates inflammation and tissue injury in nephrotoxicity. J Am Soc Nephrol 19: 923-932, 2008.

12. Faubel S, Lewis EC, Reznikov L, Ljubanovic D, Hoke TS, Somerset H, Oh DJ, Lu L, Klein CL, Dinarello CA and Edelstein CL: Cisplatin-induced acute renal failure is associated with an increase in the cytokines interleukin (IL)-1beta, IL-18, IL-6, and neutrophil infiltration in the kidney. J Pharmacol Exp Ther 322: 8-15, 2007.

13. Deng J, Kohda Y, Chiao H, Wang Y, Hu X, Hewitt SM, Miyaji T, McLeroy P, Nibhanupudy B, Li S and Star RA: Interleukin-10 inhibits ischemic and cisplatin-induced acute renal injury. Kidney Int 60: 2118-2128, 2001.

14. Ni J, Hou X, Wang X, Shi Y, Xu L, Zheng X, Liu N, Qiu A and Zhuang S: 3-deazaneplanocin A protects against cisplatin-induced renal tubular cell apoptosis and acute kidney injury by restoration of E-cadherin expression. Cell Death Dis 10: 355, 2019.

15. Lu QB, Du Q, Wang HP, Tang ZH, Wang YB and Sun HJ: Salusin- $\beta$ mediates tubular cell apoptosis in acute kidney injury: Involvement of the PKC/ROS signaling pathway. Redox Biol 30: 101411, 2020

16. Scaffidi P, Misteli T and Bianchi ME: Release of chromatin protein HMGB1 by necrotic cells triggers inflammation. Nature 418: 191-195, 2002.

17. Wu H, Ma J, Wang P, Corpuz TM, Panchapakesan U, Wyburn KR and Chadban SJ: HMGB1 contributes to kidney ischemia reperfusion injury. J Am Soc Nephrol 21: 1878-1890, 2010.

18. Doi K, Ishizu T, Tsukamoto-Sumida M, Hiruma T, Yamashita T, Ogasawara E, Hamasaki Y, Yahagi N, Nangaku M and Noiri E: The high-mobility group protein B1-Toll-like receptor 4 pathway contributes to the acute lung injury induced by bilateral nephrectomy. Kidney Int 86: 316-326, 2014.

19. Ruan Y, Wang L, Zhao Y, Yao Y, Chen S, Li J, Guo H, Ming C, Chen S, Gong F and Chen G: Carbon monoxide potently prevents ischemia-induced high-mobility group box 1 translocation and release and protects against lethal renal ischemia-reperfusion injury. Kidney Int 86: 525-537, 2014.

20. Kim J: Poly(ADP-ribose) polymerase activation induces high mobility group box 1 release from proximal tubular cells during cisplatin nephrotoxicity. Physiol Res 65: 333-340, 2016. 
21. Zhu F, Chong Lee Shin OL, Xu H, Zhao Z, Pei G, Hu Z, Yang J, Guo Y, Mou J, Sun J, et al: Melatonin promoted renal regeneration in folic acid-induced acute kidney injury via inhibiting nucleocytoplasmic translocation of HMGB1 in tubular epithelial cells. Am J Transl Res 9: 1694-1707, 2017.

22. Leelahavanichkul A, Huang Y, Hu X, Zhou H, Tsuji T, Chen R, Kopp JB, Schnermann J, Yuen PST and Star RA: Chronic kidney disease worsens sepsis and sepsis-induced acute kidney injury by releasing high mobility group box protein-1. Kidney Int 80 : $1198-1211,2011$.

23. Wei Q, Dong G, Franklin J and Dong Z: The pathological role of Bax in cisplatin nephrotoxicity. Kidney Int 72: 53-62, 2007.

24. Cho HJ, Kim JK, Kim KD, Yoon HK, Cho MY, Park YP, Jeon JH, Lee ES, Byun SS, Lim HM, et al: Upregulation of Bcl-2 is associated with cisplatin-resistance via inhibition of Bax translocation in human bladder cancer cells. Cancer Lett 237: 56-66, 2006.

25. Nagothu KK, Bhatt R, Kaushal GP and Portilla D: Fibrate prevents cisplatin-induced proximal tubule cell death. Kidney Int 68: 2680-2693, 2005.

26. Morigi M, Rota C, Montemurro T, Montelatici E, Cicero VL, Imberti B, Abbate M, Zoja C, Cassis P, Longaretti L, et al: Life-sparing effect of human cord blood-mesenchymal stem cells in experimental acute kidney injury. Stem Cells 28: 513-522, 2010.

27. Peired AJ, Sisti A and Romagnani P: Mesenchymal stem cell-based therapy for kidney disease: A review of clinical evidence. Stem Cells Int 2016: 4798639, 2016.

28. Jiao X, Cai J, Yu X and Ding X: Paracrine activation of the wnt $/ \beta$-catenin pathway by bone marrow stem cell attenuates cisplatin-induced kidney injury. Cell Physiol Biochem 44: 1980-1994, 2017.

29. Fang TC and Poulsom R: Cell-based therapies for birth defects: A role for adult stem cell plasticity? Birth Defects Res C Embryo Today 69: 238-249, 2003.

30. El-Ashmawy NE, Khedr EG, El-Bahrawy HA and El-Berashy SA: Effect of human umbilical cord blood-derived mononuclear cells on diabetic nephropathy in rats. Biomed Pharmacother 97: 1040-1045, 2018

31. Pimentel-Coelho PM, Rosado-de-Castro PH, da Fonseca LM and Mendez-Otero R: Umbilical cord blood mononuclear cell transplantation for neonatal hypoxic-ischemic encephalopathy. Pediatr Res 71: 464-473, 2012.

32. Cui X, Chen L, Xue T, Yu J, Liu J, Ji Y and Cheng L: Human umbilical cord and dental pulp-derived mesenchymal stem cells: Biological characteristics and potential roles in vitro and in vivo. Mol Med Rep 11: 3269-3278, 2015.

33. Pittenger MF, Mackay AM, Beck SC, Jaiswal RK, Douglas R, Mosca JD, Moorman MA, Simonetti DW, Craig S and Marshak DR: Multilineage potential of adult human mesenchymal stem cells. Science 284: 143-147, 1999

34. Rubinstein P, Dobrila L, Rosenfield RE, Adamson JW, Migliaccio G, Migliaccio AR, Taylor PE and Stevens CE: Processing and cryopreservation of placental/umbilical cord blood for unrelated bone marrow reconstitution. Proc Natl Acad Sci USA 92: 10119-10122, 1995.

35. Seo Y, Yang SR, Jee MK, Joo EK, Roh KH, Seo MS, Han TH, Lee SY, Ryu PD, Jung JW, et al: Human umbilical cord blood-derived mesenchymal stem cells protect against neuronal cell death and ameliorate motor deficits in Niemann Pick type $\mathrm{C} 1$ mice. Cell Transplant 20: 1033-1047, 2011.

36. Duan SB, Liu GL, Chen GC, Wang P, Pan P and Xu XQ: Aged rats are susceptible to nephrotoxicity induced by iodinated contrast media. Ren Fail 35: 150-154, 2013

37. Schetza M, Dastab J, Goldsteinc S and Golperd T: Drug-induced acute kidney injury. Curr Opin Crit Care 11: 555-565, 2005.

38. Launay-Vacher V, Rey JB, Isnard-Bagnis C, Deray G and Daouphars M; European Society of Clinical Pharmacy Special Interest Group on Cancer Care: Prevention of cisplatin nephrotoxicity: State of the art and recommendations from the european society of clinical pharmacy special interest group on cancer care. Cancer Chemother Pharmacol 61: 903-909, 2008.
39. Perazella MA and Moeckel GW: Nephrotoxicity from chemotherapeutic agents: Clinical manifestations, pathobiology, and prevention/therapy. Semin Nephrol 30: 570-581, 2010.

40. Freitag J, Bates D, Boyd R, Shah K, Barnard A, Huguenin L and Tenen A: Mesenchymal stem cell therapy in the treatment of osteoarthritis: Reparative pathways, safety and efficacy-a review. BMC Musculoskelet Disord 17: 230, 2016.

41. Eom YW, Shim KY and Baik SK: Mesenchymal stem cell therapy for liver fibrosis. Korean J Intern Med 30: 580-589, 2015

42. Bagno L, Hatzistergos KE, Balkan W and Hare JM: Mesenchymal stem cell-based therapy for cardiovascular disease: Progress and challenges. Mol Ther 26: 1610-1623, 2018.

43. Mendt M,RezvaniK and ShpallE: Mesenchymal stem cell-derived exosomes for clinical use. Bone Marrow Transplant 54 (Suppl 2): S789-S792, 2019.

44. Morigi M, Imberti B, Zoja C, Corna D, Tomasoni S, Abbate M, Rottoli D, Angioletti S, Benigni A, Perico N, et al: Mesenchymal stem cells are renotropic, helping to repair the kidney and improve function in acute renal failure. J Am Soc Nephrol 15: 1794-1804, 2004.

45. Eliopoulos N, Zhao J, Forner K, Birman E, Young YK and Bouchentouf $\mathrm{M}$ : Erythropoietin gene-enhanced marrow mesenchymal stromal cells decrease cisplatin-induced kidney injury and improve survival of allogeneic mice. Mol Ther 19: 2072-2083, 2011.

46. Park JH, Jang HR, Kim DH, Kwon GY, Lee JE, Huh W, Choi SJ, Oh W, Oh HY and Kim YG: Early, but not late, treatment with human umbilical cord blood-derived mesenchymal stem cells attenuates cisplatin nephrotoxicity through immunomodulation. Am J Physiol Renal Physiol 313: F984-F996, 2017.

47. Lee RH, Song JM, Park MY, Kang SK, Kim YK and Jung JS: Cisplatin-induced apoptosis by translocation of endogenous Bax in mouse collecting duct cells. Biochem Pharmacol 62: 1013-1023, 2001.

48. Phinney DG and Prockop DJ: Concise review: Mesenchymal stem/multipotent stromal cells: The state of transdifferentiation and modes of tissue repair-current views. Stem Cells 25: 2896-2902, 2007.

49. Herrera MB, Bussolati B, Bruno S, Fonsato V, Romanazzi GM and Camussi G: Mesenchymal stem cells contribute to the renal repair of acute tubular epithelial injury. Int J Mol Med 14: 1035-1041, 2004.

50. Tögel F, Weiss K, Yang Y, Hu ZM, Zhang P and Westenfelder C: Vasculotropic, paracrine actions of infused mesenchymal stem cells are important to the recovery from acute kidney injury. Am J Physiol Renal Physiol 292: F1626-F1635, 2007.

51. Tögel F, Zhang P, Hu ZM and Westenfelder C: VEGF is a mediator of the renoprotective effects of multipotent marrow stromal cells in acute kidney injury. J Cell Mol Med 13: 2109-2114, 2009.

52. Zhou Y, Xu H, Xu W, Wang B, Wu H, Tao Y, Zhang B, Wang M Mao F, Yan Y, et al: Exosomes released by human umbilical cord mesenchymal stem cells protect against cisplatin-induced renal oxidative stress and apoptosis in vivo and in vitro. Stem Cell Res Ther 4: 34, 2013

53. Zhang G, Zou X, Huang Y, Wang F, Miao S, Liu G, Chen M and Zhu Y: Mesenchymal stromal cell-derived extracellular vesicles protect against acute kidney injury through anti-oxidation by enhancing Nrf2/ARE activation in rats. Kidney Blood Press Res 41: 119-128, 2016.

This work is licensed under a Creative Commons Attribution-NonCommercial-NoDerivatives 4.0 International (CC BY-NC-ND 4.0) License. 